\title{
Iron supplementation for children: Safety in all settings is not clear
}

\author{
Katherine Gray-Donald PhD
}

See related research article by Low and colleagues on page E791 and at www.cmaj.ca/lookup/doi/10.1503/cmaj.130628

I $\mathrm{n}$ a linked research article, Low and colleagues present the findings of their metaanalysis of randomized trials that examined the effect of iron supplementation on cognitive function and other health indicators in primaryschool-aged children. ${ }^{1}$ The findings of this well-done and important study show that children who received iron supplementation had better improvement on global cognitive performance and IQ tests compared with children who received a placebo; this effect was observed among children with anemia at the start of the trials but not among those without anemia. However, as the authors clearly point out, the included studies were almost exclusively from low- and middle-income countries. The relevance of the study's findings to Canadian children is not clear. The safety of routine iron supplementation in children has not been well-established, and determining the best ways to improve iron status in different settings still needs to be addressed.

The magnitude of the effect of iron supplementation on cognitive performance in the metaanalysis by Low and colleagues is impressive; they report a mean difference in IQ among children with anemia of 4.55 (95\% confidence interval [CI] 0.16-8.94) between iron supplementation and control groups. Supplementation improved iron indicators, yet there was not a great deal of evidence that growth was enhanced. This meta-analysis points to the importance of iron deficiency anemia as a nutritional problem in the settings studied and the consequences of such deficiency for cognitive development. Iron deficiency anemia is an important global problem with well-substantiated health consequences that should be of particular interest to those in the education sector.

The Canadian Health Measures Survey, a population-based national sample of Canadians, provides recent hemoglobin data for Canada. Among children aged 6-11 years, $96.9 \%$ of boys and $97.1 \%$ of girls had hemoglobin values that indicate sufficient hemoglobin levels; this is sim- ilar to the data from the previous nutrition survey performed in $1970 .^{2}$ The mean hemoglobin values of just over $130 \mathrm{~g} / \mathrm{L}$ among children aged 611 years in Canada is a far cry from the baseline values reported in the low- and middle-income countries where the trials included in this metaanalysis took place (although the baseline levels were often not known). In Canada, there are reports of a high prevalence of anemia in some remote aboriginal communities, ${ }^{3}$ but these reports tend to be from settings where foods that are complementary to breastfeeding are low in iron; preschool Inuit children have low rates of iron deficiency anemia. ${ }^{4}$ Because so few children in Canada are anemic, population-level interventions are obviously not advised for primaryschool-aged children.

As Low and colleagues point out, ${ }^{1}$ the studies that they examined do not have sufficient data to rule out adverse effects of iron supplementation, and the challenges of testing for anemia in some settings in low-income countries is clearly highlighted. This raises the important question of the safety of routine iron supplementation for all children in areas where there is a high prevalence of anemia. Establishing safety is a challenge that is often underestimated. The 4 studies that included malarial infection as an outcome had a total sample size of 909 children, and the risk ratio for malarial infection among those who received iron supplementation was 1.10 (95\% CI 0.94-1.29). There is clearly insufficient statistical power to robustly establish a clinically important difference, but a $10 \%$ higher risk of malaria with iron

\section{- KeY POINTS}

- There is strong evidence that iron supplementation improves cognitive scores among anemic primary-school-aged children in low-income countries.

- Canadian children have a very low risk of anemia; routine iron supplementation programs are not needed in Canada.

- The best way of safely improving iron status among children in lowincome countries is controversial, particularly because gains in cognitive scores only occur among children with anemia. 
supplementation in endemic settings could be important. The risk ratio for gastrointestinal upset was 1.30 (95\% CI 0.89-1.91). Again, there was insufficient power to show clearly that this was not just a chance finding. Although the data related to cognitive performance are important, it is not yet known whether routine iron supplementation brings with it the risk of important adverse outcomes, and it would be prudent to exercise caution. Children without anemia did not show any cognitive improvement, so it would be important not to put nonanemic children at any risk, even though it may be costly to measure anemia in some settings. Much remains to be learned about the advisability of iron supplementation, particularly in areas where malaria is endemic, as clearly outlined by Prentice and Cox..$^{5}$

Although randomized trials have been essential to show the efficacy of iron in increasing cognitive performance, the best way to achieve increased iron intake in low-income settings requires a great deal more study. How best to address the problem of iron deficiency anemia is complex. We need to know the reasons for low hemoglobin levels in each setting because infection may be more important than iron deficiency in some areas. ${ }^{6}$ Identifying and addressing the correct problem in different settings are essential before offering solutions. Interestingly, the studies included in the meta-analysis by Low and colleagues $^{1}$ used different dosages of iron in different settings; for example, dosages ranged from as low as $5 \mathrm{mg}$ up to $400 \mathrm{mg}$ of ferrous sulfate per day. The World Health Organization currently recommends weekly iron supplementation of $45 \mathrm{mg}$ of elemental iron in areas where anemia rates exceed $20 \% .^{7}$ The weekly, rather than daily, supplementation regimen is proposed to reduce gastrointestinal adverse outcomes. The uptake of this relatively new recommendation is not well-documented, and sustainability of such interventions remains a challenge.

In addition to single or multiple nutrient supplementation, a number of other strategies to improve nutrient intake can be used. Fortification of a widely used food that is produced in central settings (e.g., flour) can increase iron intake among many people of all ages. More broadly, providing better nutrition through school-based feeding programs also has the potential to improve iron status among children, depending on the foods offered. The World Food Program Home Grown School Feeding initiative aims to improve nutrition at schools using local agricultural products. Incorporating more iron-rich foods, from both vegetable and animal sources, is an important way to achieve food security across the globe. The United Nation World Food Programme supports school-lunch programs in many areas of the world and has extensive reach. ${ }^{8}$

The meta-analysis by Low and colleagues ${ }^{1}$ is important in that it quantifies the robust effects of iron supplementation on cognitive performance among anemic children who are iron deficient. The next challenge is to determine how to safely, economically and sustainably provide better iron nutrition to children in many poor settings of the world. Clearly anemic children will benefit, but the risks of iron for all remain to be elucidated.

\section{References}

1. Low M, Farrell A, Biggs B-A, et al. Effects of daily iron supplementation in primary school-aged children: systematic review and meta-analysis of randomized controlled trials. CMAJ 2013;185:1487-94.

2. Cooper M, Greene-Finestone L, Lowell H, et al. Iron sufficiency of Canadians. Health Rep 2012;23:41-8.

3. Willows ND, Morel J, Gray-Donald K. Prevalence of anemia among James Bay Cree infants of northern Quebec. CMAJ 2000;162:323-6.

4. Pacey A, Weiler H, Egeland GM. Low prevalence of iron-deficiency anaemia among Inuit preschool children: Nunavut Inuit Child Health Survey, 2007-2008. Public Health Nutr 2011;14:1415-23.

5. Prentice AM, Cox SE. Iron and malaria interactions: research needs from basic science to global policy. Adv Nutr 2012;3:583-91.

6. Pasricha SR, Drakesmith H, Black J, et al. Control of iron deficiency anemia in low- and middle-income countries. Blood 2013;121:2607-17.

7. Intermittent iron supplementation in preschool and school-age children. Geneva (Switzerland): World Health Organization; 2011. Available: http://whqlibdoc.who.int/publications/2011 19789241502009 eng.pdf (accessed 2013 Aug. 5).

8. Home-grown school feeding: a framework to link school feeding with local agricultural production. Rome (Italy): World Food Programme; 2009. Available: http://documents.wfp.org/stellent/groups/public/documents/newsroom/wfp204291.pdf (accessed 2013 Aug. 5).

Affiliation: School of Dietetics and Human Nutrition, McGill University, Montréal, Que. 